\title{
Future Prospects for Neisseria gonorrhoeae Treatment
}

\author{
Beatriz Suay-García (iD) and María Teresa Pérez-Gracia * (i) \\ Área de Microbiología, Departamento de Farmacia, Instituto de Ciencias Biomédicas, \\ Facultad de Ciencias de la Salud, Universidad CEU Cardenal Herrera, C/Santiago Ramón y Cajal, \\ 46115 Alfara del Patriarca, Valencia, Spain; bea.suay.ce@ceindo.ceu.es \\ * Correspondence: teresa@uchceu.es; Tel.: +34-96-136-9000; Fax: +34-96-139-5272
}

Received: 22 May 2018; Accepted: 14 June 2018; Published: 15 June 2018

\begin{abstract}
Gonorrhea is a sexually transmitted disease with a high morbidity burden. Incidence of this disease is rising due to the increasing number of antibiotic-resistant strains. Neisseria gonorrhoeae has shown an extraordinary ability to develop resistance to all antimicrobials introduced for its treatment. In fact, it was recently classified as a "Priority 2" microorganism in the World Health Organization (WHO) Global Priority List of Antibiotic-Resistant Bacteria to Guide Research, Discovery and Development of New Antibiotics. Seeing as there is no gonococcal vaccine, control of the disease relies entirely on prevention, diagnosis, and, especially, antibiotic treatment. Different health organizations worldwide have established treatment guidelines against gonorrhea, mostly consisting of dual therapy with a single oral or intramuscular dose. However, gonococci continue to develop resistances to all antibiotics introduced for treatment. In fact, the first strain of super-resistant $N$. gonorrhoeae was recently detected in the United Kingdom, which was resistant to ceftriaxone and azithromycin. The increase in the detection of resistant gonococci may lead to a situation where gonorrhea becomes untreatable. Seeing as drug resistance appears to be unstoppable, new treatment options are necessary in order to control the disease. Three approaches are currently being followed for the development of new therapies against drug-resistant gonococci: (1) novel combinations of already existing antibiotics; (2) development of new antibiotics; and (3) development of alternative therapies which might slow down the appearance of resistances. N. gonorrhoeae is a public health threat due to the increasing number of antibiotic-resistant strains. Current treatment guidelines are already being challenged by this superbug. This has led the scientific community to develop new antibiotics and alternative therapies in order to control this disease.
\end{abstract}

Keywords: Neisseria gonorrhoeae; antibiotic resistance; gonorrhea; treatment

\section{Introduction}

Gonorrhea is a sexually transmitted disease (STD) caused by the obligate human pathogen Neisseria gonorrhoeae. This disease has a high morbidity burden, with more than 106 million new cases being diagnosed every year worldwide [1]. In fact, this morbidity is increasing exponentially due to the fact that gonococci have an extraordinary ability to develop resistances to all antimicrobials introduced for its treatment (Figure 1) [2-4].

The issue with drug-resistant $N$. gonorrhoeae has become such that the Centers for Disease Control (CDC) classified it as a "superbug" in 2012, announcing a near future in which gonorrhea would become untreatable [5]. Furthermore, the World Health Organization (WHO) classified it as a "Priority 2" microorganism in the recently published WHO Global Priority List of Antibiotic-Resistant Bacteria to Guide Research, Discovery, and Development of New antibiotics [6]. This document highlights the importance of developing new antibiotics to treat this disease, seeing as the existence of $N$. gonorrhoeae strains resistant to third generation cephalosporins and fluoroquinolones have already been reported. 
In fact, failure of current dual therapy was detected in the United Kingdom in 2016. More importantly, the first "super-resistant" strains were recently reported in the United Kingdom and Australia, showing resistance against the current first line treatment, dual therapy with azithromycin and ceftriaxone $[7,8]$.

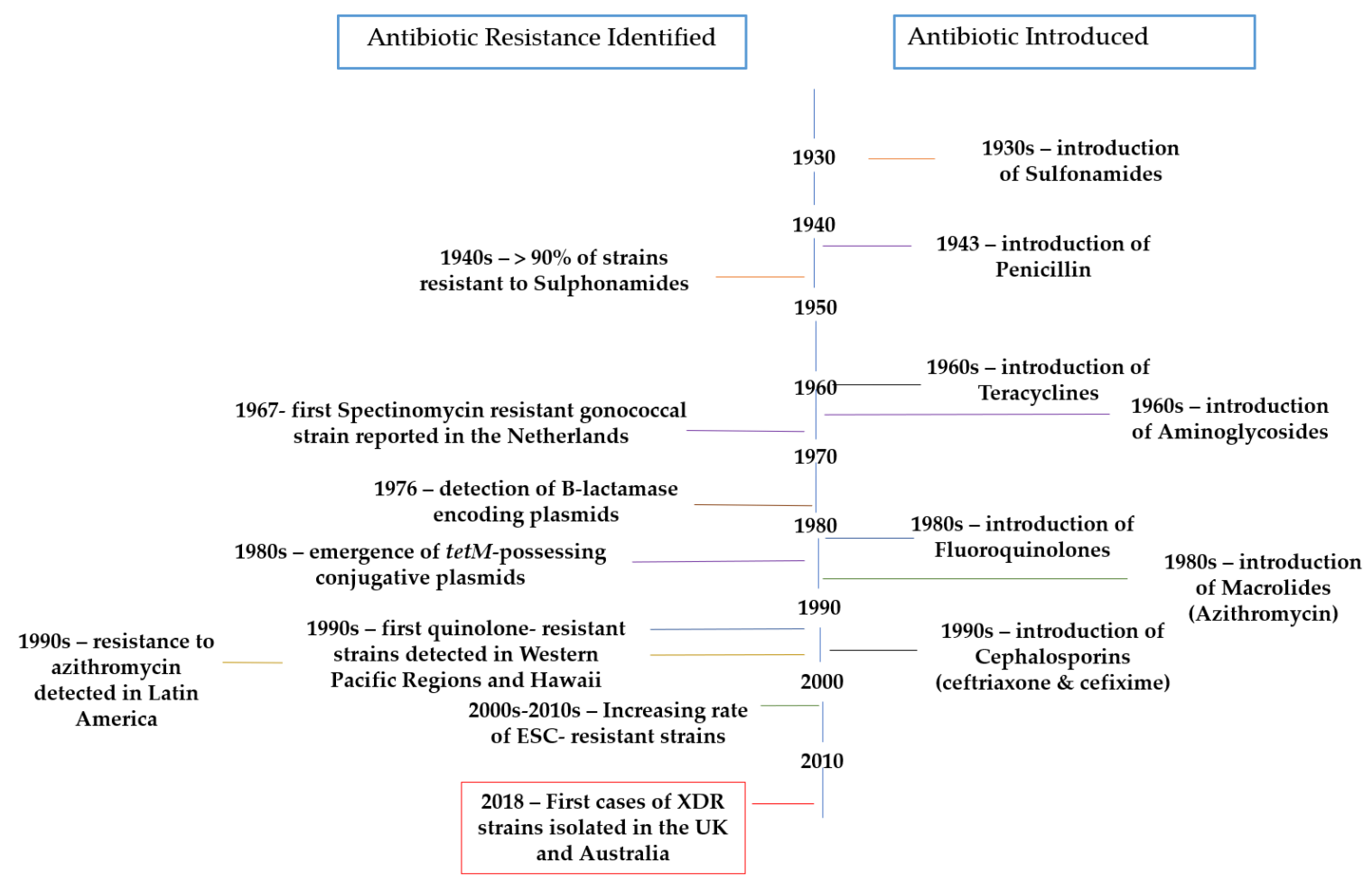

Figure 1. Timeline representing the introduction of treatments used against gonorrhea (right) and the first reports of resistance (left) $[4,7,8]$.

Seeing as there is no gonococcal vaccine, control of the disease relies entirely on prevention, diagnosis, and, especially, antibiotic treatment [9]. It is for this reason that the present review focuses on current treatment options and the future perspectives for the treatment of this disease.

\section{Current Treatment}

Generally, treatment for gonococcal infection is given at the first clinical visit, which implies that antimicrobial susceptibility is rarely performed prior to prescription. According to WHO guidelines [10], first-line antimicrobial therapy must be highly effective, widely available and affordable, lack toxicity, comprise a single dose, and rapidly cure at least $>95 \%$ of infected patients.

Different health organizations worldwide have established treatment guidelines against gonorrhea, mostly consisting of dual therapy with a single oral or intramuscular dose of a third-generation cephalosporin (250-500 mg intramuscular (IM) ceftriaxone or $400 \mathrm{mg}$ per os-oral (PO) cefixime) in combination with a single oral dose of 1-2 $\mathrm{g}$ of azithromycin [11-17] (Table 1).

However, as it was mentioned earlier, these treatment options will not be useful in the near future, as they have already been reported as ineffective in treating some patients $[7,8,18]$. With this in mind, it is evident that, in the absence of a vaccine, the future control of this disease relies completely on the development of new antibiotics and alternative treatments. 
Table 1. Different treatment guidelines for gonorrhea worldwide (all single dose).

\begin{tabular}{|c|c|c|c|c|c|c|}
\hline WHO * [11] & Australasia [12] & Canada [13] & USA [14] & UK [15] & EU [16] & New Zealand [17] \\
\hline $\begin{array}{c}\text { Ceftriaxone } 250 \mathrm{mg} \text { IM } \\
+ \\
\text { Azithromycin } 1 \mathrm{~g} \text { PO } \\
\mathrm{Or}^{* *} \\
\text { Cefixime } 400 \mathrm{mg} \text { PO } \\
+ \\
\text { Azithromycin } 1 \mathrm{~g} \text { PO }\end{array}$ & $\begin{array}{c}\text { Cetriaxone } 500 \mathrm{mg} \mathrm{IM} \\
+ \\
\text { Azithromycin } 1 \mathrm{~g} \text { PO }\end{array}$ & $\begin{array}{c}\text { Ceftriaxone } 250 \text { mg IM } \\
+ \\
\text { Azithromycin } 1 \mathrm{~g} \text { PO }\end{array}$ & $\begin{array}{c}\text { Ceftriaxone } 250 \text { mg IM } \\
+ \\
\text { Azithromycin } 1 \mathrm{~g} \text { PO }\end{array}$ & $\begin{array}{c}\text { Ceftriaxone } 500 \mathrm{mg} \mathrm{IM} \\
+ \\
\text { Azithromycin } 1 \mathrm{~g} \mathrm{PO}\end{array}$ & $\begin{array}{c}\text { Ceftriaxone } 500 \text { mg IM } \\
+ \\
\text { Azithromycin } 1 \mathrm{~g} \text { PO }\end{array}$ & $\begin{array}{c}\text { Ceftriaxone } 250 \mathrm{mg} \text { IM } \\
+ \\
\text { Azithromycin } 1 \mathrm{~g} \text { PO }\end{array}$ \\
\hline 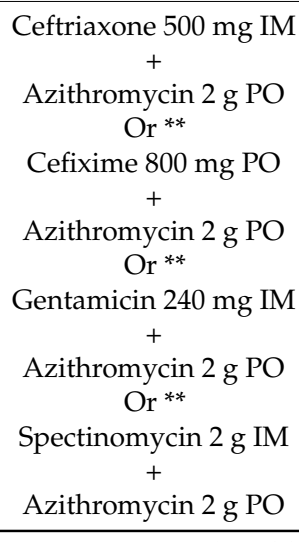 & & $\begin{array}{c}\text { Cefixime } 800 \text { mg PO } \\
+ \\
\text { Azithromycin } 1 \mathrm{~g} \mathrm{PO} \\
\quad \text { Or } * * \\
\text { Spectinomycin } 2 \mathrm{~g} \mathrm{IM} \\
\quad+ \\
\text { Azithromycin } 1 \mathrm{~g} \mathrm{PO}\end{array}$ & $\begin{array}{c}\text { Cefixime } 400 \mathrm{mg} \text { PO } \\
+ \\
\text { Azithromycin } 1 \mathrm{~g} \text { PO }\end{array}$ & $\begin{array}{c}\text { Cefixime } 400 \text { mg PO } \\
+ \\
\text { Azithromycin } 1 \mathrm{~g} \text { PO } \\
\text { Or } \\
\text { Spectinomycin } 2 \mathrm{~g} \mathrm{IM} \\
+ \\
\text { Azithromycin } 1 \mathrm{~g} \text { PO } \\
\text { Or ** } \\
\text { Cefotaxime } 500 \mathrm{mg} \mathrm{IM} \\
+ \\
\text { Azithromycin } 1 \mathrm{~g} \text { PO }\end{array}$ & $\begin{array}{c}\text { Cefixime } 400 \text { mg PO } \\
+ \\
\text { Azithromycin } 2 \text { g PO } \\
\text { Or }{ }^{* *} \\
\text { Spectinomycin } 2 \text { g IM } \\
+ \\
\text { Azithromycin } 2 \text { g PO }\end{array}$ & $\begin{array}{c}\text { Spectinomycin } 2 \mathrm{~g} \mathrm{IM} \\
+ \\
\text { Azithromycin } 1 \mathrm{~g} \mathrm{PO} \\
\text { Or } \\
\text { G* } \\
\text { Gentamicin } 240 \mathrm{mg} \mathrm{IM} \\
+ \\
\text { Azithromycin } 2 \mathrm{~g} \mathrm{PO}\end{array}$ \\
\hline
\end{tabular}

* WHO (World Health Organization); IM (Intramuscular); PO (Per os-oral) ** An "or" between combinations means that any of those combinations may be prescribed 


\section{Future Perspectives}

Seeing as drug resistance appears to be unstoppable, new treatment options are necessary in order to control the disease [19]. Three approaches are currently being followed for the development of new therapies against drug-resistant gonococci: (1) novel combinations of already existing antibiotics; (2) development of new antibiotics; and (3) development of alternative therapies, which might slow down the appearance of resistances (Table 2).

Table 2. Antigonococcal agents currently under development.

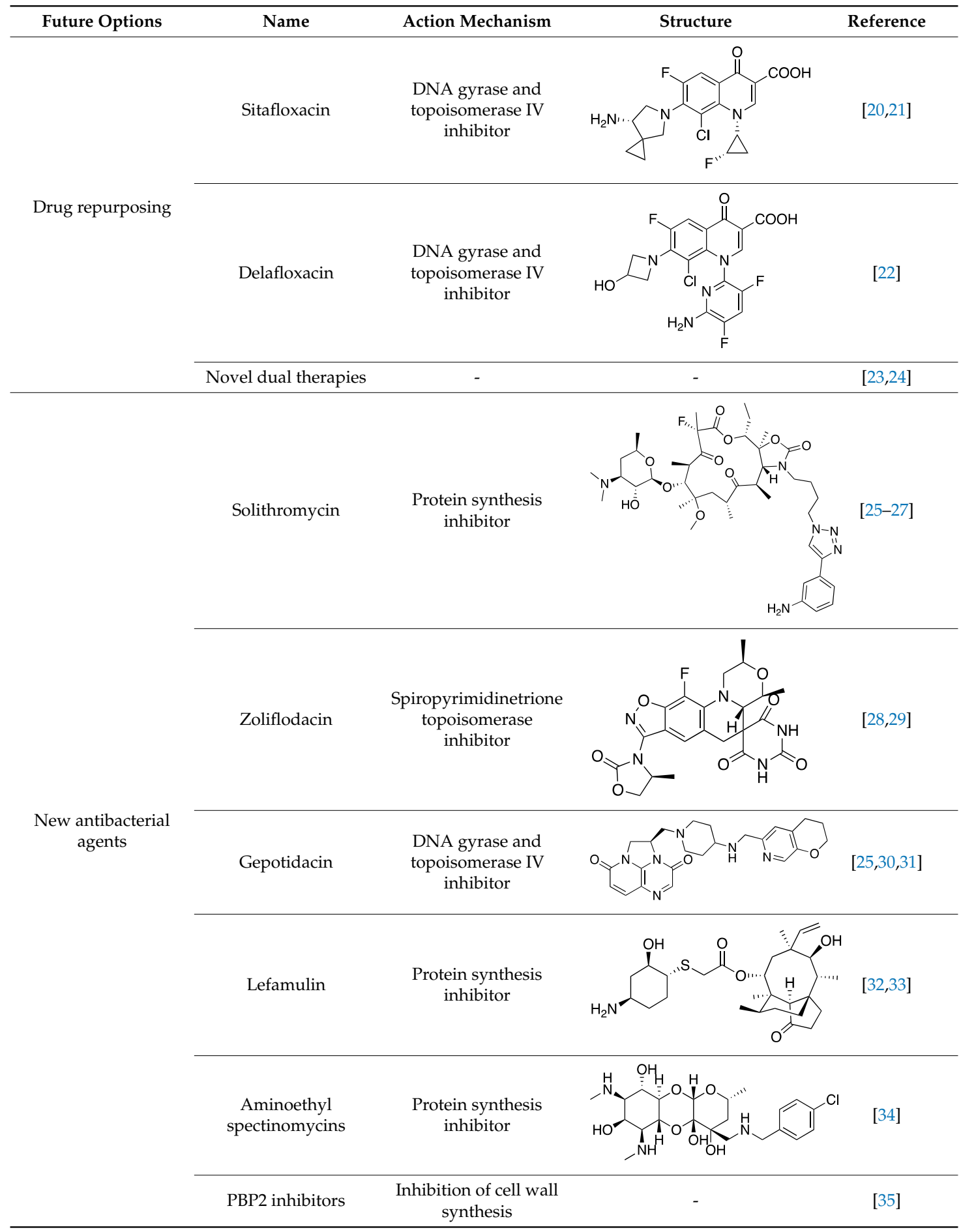


Table 2. Cont.

\begin{tabular}{ccccc}
\hline Future Options & Name & Action Mechanism & Structure & Reference \\
\hline & IL-12 & $\begin{array}{c}\text { Induction of immune } \\
\text { response }\end{array}$ & [36] \\
\cline { 2 - 5 } Alternative therapies & $\begin{array}{c}\text { Biosurfactant and } \\
\text { acidic environment } \\
\text { Mactobacillus crispatus } \\
\text { Myristoleic acid }\end{array}$ & $\begin{array}{c}\text { Cell membrane } \\
\text { disruption }\end{array}$ & [37] \\
\cline { 2 - 5 } & $\begin{array}{c}\text { Bacteriophage } \\
\text { therapy }\end{array}$ & Lysis & [38,39] \\
\hline
\end{tabular}

\subsection{Repurposing of Already Existing Antibiotics}

Considering the fact that untreatable gonorrhea has indeed become a reality, the need for new treatment options has become a pressing issue. For this reason, the scientific community has turned to trying new combinations of already existing antibiotics as the fastest way to fight multi-resistant superbugs. Along these lines, Jönsson et al. studied the viability of introducing sitafloxacin, a newer-generation broad spectrum fluoroquinolone mostly used for respiratory infections, as part of a dual therapy against gonococci [20]. In the study, sitafloxacin was tested against a global gonococcal panel of 250 isolates, showing a rapid bactericidal effect with a Minimum Inhibitory Concentration (MIC) range of $\leq 0.001-1 \mathrm{mg} / \mathrm{L}$. These results prove that sitafloxacin is a good candidate to be included in dual antimicrobial therapy for gonorrhea in cases with cephalosporin resistance or allergy.

Along these lines, another study focuses on the evaluation of sitafloxacin and five additional fluoroquinolones against ciprofloxacin-resistant $N$. gonorrhoeae isolates [21]. The in vitro potency of sitafloxacin was substantially higher compared with the other five fluoroquinolones, with an MIC range of $0.03-0.5 \mathrm{mg} / \mathrm{L}$ against the ciprofloxacin-resistant strains. These results further confirm the utility of sitafloxacin in dual antimicrobial therapy.

Another fluoroquinolone currently being studied for the treatment of gonorrhea is delafloxacin [22]. Soge et al. evaluated the activity of delafloxacin against 117 strains of $N$. gonorrhoeae. The results showed an MIC range of $\leq 0.001-0.25 \mu \mathrm{g} / \mathrm{mL}$, which is higher than that of ciprofloxacin, penicillin, tetracycline, azithromycin, and spectinomycin. Further studies are required to correlate these promising in vitro results with clinical treatment outcomes.

On a similar note, Singh et al. assayed the potent utility of in vitro interactions of 21 dual therapy combinations against $95 \mathrm{~N}$. gonorrhoeae strains [23]. Of these 21 combinations, five were novel introductions that are not included in any existing guidelines: gentamicin + ertapenem, moxifloxacin + ertapenem, spectinomycin + ertapenem, azithromycin + moxifloxacin, and cefixime + gentamicin. All five novel combinations produced high synergistic effects against the studied strains, which suggests that further in vivo evaluation in clinical trials should be performed in order to include these combinations for future treatment of gonorrhea.

Gentamicin is already included in several guidelines in combination with azithromycin as an alternative treatment option when main treatment options fail. A recent study examines the synergistic effect of this combination along with gentamicin combined with five other antimicrobials (cefixime, ceftriaxone, spectinomycin, azithromycin, moxifloxacin, and ertapenem) [24]. The study concludes that gentamicin in combination with ertapenem or cefixime could be introduced as new antimicrobial dual therapy seeing as these combinations showed maximum efficacy and synergism against 75 gonococcal strains. 


\subsection{New Antibiotics}

However, seeing as gonococci have proven to be able to develop resistances to all antibiotics introduced for their treatment, the long-term solution includes the development of new antibiotics. Ideally, these new antibiotics should belong to antibacterial families different to the ones already included in treatment guidelines in order to delay the appearance of resistances as much as possible.

Along these lines, WHO launched the Global Antibiotic Research and Development Partnership (GARDP) in order to work with experts to draw a plan to meet the urgent need for new drugs to treat gonorrhea [25]. Within this partnership, experts analyze current drugs in clinical development for the treatment of this disease. Currently, only three molecules have reached clinical trials: Solithromycin, Zoliflodacin, and Gepotidacin.

Solithromycin is a broad-spectrum oral fluoroketolide which targets three prokaryotic ribosomal sites [26]. In vitro studies against 246 clinical isolates and international reference strains of $N$. gonorrhoeae showed promising results, with an MIC range of $0.001-32 \mu \mathrm{g} / \mathrm{mL}$, showing more activity than the antimicrobials currently recommended for its treatment. Phase II clinical trials concluded with $100 \%$ efficacy for infection in men and women for all studied sites (genital, oral, and rectal) [27]. This drug is currently in Phase III trials.

As for Zoliflodacin, it has a novel action mechanism by which it inhibits the spiropyrimidinetrione topoisomerase [28]. Early in vitro studies showed promising results, with the compound being highly effective against clinical isolates from 21 European countries [29]. Zoliflodacin showed an MIC range of $\leq 0.002-0.25 \mu \mathrm{g} / \mathrm{mL}$, considerably lower than that of most drugs currently being used for treatment but, most importantly, it did not present any cross-resistance to these antimicrobials.

Similarly, Farrell et al. studied the antigonococcal activity of Gepotidacin, a novel triazaacenaphthylene antibacterial which inhibits bacterial DNA gyrase and topoisomerase IV via a unique mechanism [30,42]. The compound had an $\mathrm{MIC}_{50}$ and $\mathrm{MIC}_{90}$ of 0.12 and $0.25 \mathrm{mg} / \mathrm{L}$, respectively, against $25 \mathrm{~N}$. gonorrhoeae strains, including five ciprofloxacin non-susceptible strains. Moreover, synergism studies showed that no antagonism occurred when gepotidacin was combined with levofloxacin, azithromycin, tetracycline, and ceftriaxone; while the combination of gepotidacin with moxifloxacin had a synergistic effect. This drug candidate underwent a Phase II evaluation, showing that oral doses of gepotidacin were $\geq 95 \%$ effective in treating uncomplicated urogenital gonorrhea [31].

Along with these three drugs in clinical trials, other compounds being developed to treat gonorrhea are still in early experimental phases. This is the case of Lefamulin, a novel semi-synthetic pleuromutilin, recently evaluated against 251 gonococcal clinical isolates, including multidrug-resistant and extensively-drug resistant samples [32]. The compound showed potent activity, an MIC range of $0.004-2 \mathrm{mg} / \mathrm{L}$, against gonococcal isolates and no significant cross-resistance to other antimicrobials. Furthermore, this compound has also been proven to be active against the other most relevant bacterial pathogens causing sexually transmitted infections (STIs), Chlamydia trachomatis and Mycoplasma genitalium, proving to be a good candidate first-line antibiotic for the treatment of STIs [33]. However promising, further studies are required in order to consider the introduction of Lefamulin as a first-line treatment option.

For that matter, Butler et al. studied aminoethyl spectinomycins, a new class of semisynthetic analogs of the antibiotic spectinomycin, for the treatment of drug-resistant gonococci [34]. The studied compounds presented increased potency against $N$. gonorrhoeae compared to spectinomycin. Furthermore, these compounds also demonstrated activity against $C$. trachomatis, which is not observed with spectinomycin. The study concludes that aminoethyl spectinomycins are a promising alternative for spectinomycin and antibiotics such as ceftriaxone against drug-resistant gonorrhea, with the added benefit of treating chlamydial co-infections.

Furthermore, novel antibacterials in the earliest stages of drug design and screening have also been reported. Fedarovich et al. screened a 50,000 compound library for potential inhibitors of N. gonorrhoeae penicillin binding protein 2 (PBP 2) using fluorescence polarization [35]. The screening 
resulted in 32 compounds exhibiting $>50 \%$ inhibition of Bocillin-FL binding to PBP 2 , of which seven showed antimicrobial activity against susceptible and penicillin- or cephalosporin-resistant strains. These seven molecules remain as lead compounds for future optimization as anti-gonococcal agents.

\subsection{Alternative Therapies}

In addition to new antibiotics, alternative therapies to combat increasingly resistant $N$. gonorrhoeae are being developed. These alternatives are mainly focused on the prevention of recurring infections rather than on the treatment of the disease. In this regard, early in vivo studies have been performed regarding the intravaginal administration of interleukin-12 (IL-12) in mice [36]. The study concludes that intravaginally administered IL-12 promotes the Th1-driven adaptive immune response, including the production of specific anti-gonococcal antibodies which would prevent recurring infection.

On a similar note, Foschi et al. studied the efficacy of vaginal lactobacilli in reducing N. gonorrhoeae viability [37]. The study assessed the anti-gonococcal activity of 14 vaginal Lactobacillus strains belonging to L. crispatus, L. gasseri, and L. vaginalis. It was found that the acidic environment associated with lactobacilli metabolism is extremely effective in counteracting gonococcal growth, with complete abolishment of gonococci viability being observed at $\mathrm{pH}<4.0$. Furthermore, results showed that lactobacilli cells are able to reduce viability and co-aggregate with gonococci. This is achieved by released-surface components with biosurfactant properties produced by lactobacilli. The study concludes that specific Lactobacillus strains, mainly belonging to L. crispatus, are able to counteract gonococcal viability through multiple mechanisms, representing a new potential probiotic strategy for the prevention of infection in women.

Prophylaxis is especially important during pregnancy, seeing as neonatal conjunctivitis is commonly caused by N. gonorrhoeae [38]. The most common approach is ophthalmic prophylaxis with antibiotic ointments. However, due to the increasing appearance of resistances, these are becoming less effective. Churchward et al. studied 37 fatty acids or fatty acid derivatives for fast antigonococcal activity [39]. Two lead candidates, monocaprin and myristoleic acid, were bactericidal at $1 \mathrm{mM}$ and remained active in artificial tear fluid, becoming promising alternatives to conventional antibacterial ointments. They went on to study the ability of $N$. gonorrhoeae to develop resistance when grown in sub-lethal concentrations of monocaprin [43]. Results showed that, after growing gonococci on growth media containing sub-lethal concentrations of monocaprin, the MIC showed a two-fold change, which cannot be considered as the development of resistance. Thus, the study concludes that $N$. gonorrhoeae in not capable of developing resistances against monocaprin, making it an ideal long-term alternative for neonatal conjunctivitis prophylaxis.

Another alternative treatment that has gained importance recently is bacteriophage therapy, as a therapeutic option on its own and also in combination with currently used antimicrobials [44,45]. However promising, this type of therapy is still in early stages when it comes to treating gonorrhea. Experiments with peptide inhibitors targeting gonococci identified using phage display have been reported in recent years [40,41]. Connor et al. constructed open reading frame phagemid (pHORF) oligopeptide phage display libraries of the entire N. gonorrhoeae genome, identifying six immunogenic proteins for the first time and verifying 13 additional proteins as immunogenic in N. gonorrhoeae [40]. Similarly, Sikora et al. focused on targeting the nitrite reductase AniA, a key component of gonococcal anaerobic respiration and biofilm formation [41]. One of the 29 unique peptides identified, C7-3, and its derivative (C7-3m2), demonstrated potent inhibition of AniA, with an MIC50 value of $0.6 \mathrm{mM}$ against anaerobically grown N. gonorrhoeae. These studies show promising results towards the development of bacteriophage therapy for the treatment of gonorrhea; however, further studies are required in this field.

\section{Conclusions}

Neisseria gonorrhoeae is a public health threat worldwide due to the increasing number of antibiotic-resistant strains. Current treatment guidelines include first-line treatments, as well as 
alternative treatments which should only be prescribed in case of allergy or presence of resistance. However, most of these guidelines are already being challenged by this "Superbug". This has led the scientific community to develop new antibiotics and alternative therapies in order to control this disease. These new treatment options require not only high antigonococcal potency, but also no cross-resistance with current antibiotics in order to assure their applicability in the long-run. Alternative therapies, on the other hand, have focused on preventing infections rather than treating them and, therefore, controlling the disease before it has a chance of developing further resistances.

Author Contributions: B.S.-G. conceived and wrote the paper and M.T.P.-G. conceived and wrote the paper.

Funding: This research received no external funding.

Conflicts of Interest: The authors declare no conflict of interest.

\section{References}

1. World Health Organization (WHO). Global Action Plan to Control the Spread and Impact of Antimicrobial Resistance in Neisseria gonorrhoeae; WHO: Geneva, Switzerland, 2012; Available online: http:/ /apps.who.int/ iris/bitstream/10665/44863/1/9789241503501_eng.pdf (accessed on 15 May 2018).

2. Bolan, G.A.; Sparling, P.F.; Wasserheit, J.N. The emerging threat of untreatable gonococcal infection. N. Engl. J. Med. 2012, 366, 485-487. [CrossRef] [PubMed]

3. Hook, E.W., 3rd; Kirkcaldy, R.D. A Brief History of Evolving Diagnostics and Therapy for Gonorrhea: Lessons Learned. Clin. Infect. Dis. 2018. [CrossRef] [PubMed]

4. Unemo, M.; Del Rio, C.; Shafer, W.M. Emerging Infections 10; Scheld, W.M., Hughes, J.M., Whitley, R.J., Eds.; American Society for Microbiology: Washington, DC, USA, 2016; Chapter 12.

5. Centers for Disease Control and Prevention (CDC). Cephalosporin-Resistant Neisseria gonorrhoeae Public Health Response Plan; CDC: Atlanta, GA, USA, 2012; pp. 1-43.

6. World Health Organization (WHO). Global Priority List of Antibiotic-Resistant Bacteria to Guide Research, Discovery, and Development of New Antibiotics; WHO: Geneva, Switzerland, 2017; Available online: http:/ / www.who.int/ medicines/publications/WHO-PPL-Short_Summary_25Feb-ET_NM_WHO.pdf (accessed on 15 May 2018).

7. Public Health England. UK Case of Neisseria gonorrhoeae with High-Level Resistance to Azithromycin and Resistance to Ceftriaxone Acquired Abroad; Health Protection Report; Public Health England: London, UK, 2018; Volume 12.

8. Australian Government. Department of Health. Multi-Drug Resistant Gonorrhoea. 2018. Available online: http://www.health.gov.au/internet/main/publishing.nsf/Content/mr-yr18-dept-dept004.htm (accessed on 15 May 2018).

9. Suay-Garcia, B.; Pérez-Gracia, M.T. Drug-Resistant Neisseria gonorrhoeae: Latest developments. Eur. J. Clin. Microbiol. Infect. Dis. 2017, 36, 1065-1071. [CrossRef] [PubMed]

10. World Health Organization (WHO). Strategies and Laboratory Methods for Strengthening Surveillance of Sexually Transmitted Infections. Available online: http:/ / www.who.int/reproductivehealth/publications/ rtis/9789241504478/en/ (accessed on 22 April 2018).

11. World Health Organization (WHO). Guidelines for the Treatment of Neisseria gonorrhoeae. Available online: http://www.who.int/reproductivehealth/publications/rtis/gonorrhoea-treatment-guidelines/en/ (accessed on 22 April 2018).

12. Australasia Sexual Health Alliance. Australian STI Management Guidelines for Use in Primary Care. Available online: http:/ / www.sti.guidelines.org.au/sexually-transmissible-infections/gonorrhoea (accessed on 22 April 2018).

13. Public Health Agency of Canada. Canadian Guidelines on Sexually Transmitted Infections. Available online: https://www.canada.ca/en/public-health/services/infectious-diseases/sexual-health-sexually-transmittedinfections / canadian-guidelines/sexually-transmitted-infections/canadian-guidelines-sexually-transmittedinfections-34.html (accessed on 22 April 2018).

14. Bignell, C.; Unemo, M.; European STI Guidelines Editorial Board. European Guideline on the Diagnosis and Treatment of Gonorrhea in Adults. Int. J. STD AIDS 2013, 24, 85-92. [CrossRef] [PubMed]

15. Centers for Disease Control and Prevention (CDC). Sexually Transmitted Diseases Treatment Guidelines. Available online: https:/ /www.cdc.gov/std/tg2015/gonorrhea.htm (accessed on 22 April 2018). 
16. Bignell, C.; Fitzgerald, M.; Guideline Development Group; British Association for Sexual Health and HIV UK. UK national guideline for the management of gonorrhea in adults. Int. J. STD AIDS 2011, 22, 541-547. [CrossRef] [PubMed]

17. The New Zealand Sexual Health Society. New Zealand Guideline for the Management of Gonorrhea, 2014, and Response to the Threat of Antimicrobial Resistance. Available online: http://www.nzshs.org/docman/ guidelines/best-practice-guidelines /142-new-zealand-guideline-for-the-management-of-gonorrhoea-2014-andresponse-to-the-threat-of-antimicrobial-resistance/file (accessed on 22 April 2018).

18. Fifer, H.; Natarajan, U.; Jones, L.; Alexander, S.; Hughes, G.; Golparian, D.; Unemo, M. Failure of Dual Antimicrobial Therapy in Treatment of Gonorrhea. N. Engl. J. Med. 2016, 734, 2504-2506. [CrossRef] [PubMed]

19. Lee, H.; Lee, K.; Chong, Y. New treatment options for infections caused by increasingly antimicrobial-resistant Neisseria gonorrhoeae. Exp. Rev. Anti-Infect. Ther. 2016, 14, 243-256. [CrossRef] [PubMed]

20. Jönsson, A.; Sunniva, F.; Golparian, D.; Hamasuna, R.; Jacobsson, S.; Lindberg, M.; Jensen, J.S.; Ohnishi, M.; Unemo, M. In vitro activity and time-kill curve analysis of sitafloxacin against a global panel of antimicrobial-resistant and multidrug-resistant Neisseria gonorrhoeae isolates. APMIS 2018, 126, 29-37. [CrossRef] [PubMed]

21. Hamasuna, R.; Ohnishi, M.; Matsumoto, M.; Okumura, R.; Unemo, M.; Matsumoto, T. In vitro activity of sitafloxacin and additional newer generation Fluoroquinolones against ciprofloxacin-resistant Neisseria gonorrhoeae isolates. Microb. Drug Resist. 2018, 24, 30-34. [CrossRef] [PubMed]

22. Soge, O.O.; Salipante, S.J.; No, D.; Duffy, E.; Roberts, M.C. In Vitro Activity of Delafloxacin against Clinical Neisseria gonorrhoeae Isolates and Selection of Gonococcal Delafloxacin Resistance. Antimicrob. Agents Chemother. 2016, 60, 3106-3111. [CrossRef] [PubMed]

23. Singh, V.; Bala, M.; Bhargava, A.; Kakran, M.; Bhatnagar, R. In vitro efficacy of 21 dual antimicrobial combinations comprising novel and currently recommended combinations for treatment of drug resistant gonorrhoea in future era. PLoS ONE 2018, 13, e0193678. [CrossRef] [PubMed]

24. Singh, V.; Bala, M.; Bhargava, A.; Kakran, M.; Bhatnagar, R. In vitro synergy testing of gentamicin, an old drug suggested as future treatment option for gonorrhoea, in combination with six other antimicrobials against multidrug-resistant Neisseria gonorrhoeae strains. Sex. Transm. Dis. 2018, 45, 127-131. [CrossRef] [PubMed]

25. Alirol, E.; Wi, T.E.; Bala, M.; Bazzo, M.L.; Chen, X.S.; Deal, C.; Dillon, J.R.; Kularatne, R.; Heim, J.; Hooft van Huijsduijnen, R.; et al. Multidrug-resistant gonorrhea: A research and development roadmap to discover new medicines. PLoS Med. 2017, 14, e1002366. [CrossRef] [PubMed]

26. Golparian, D.; Fernandes, P.; Ohnishi, M.; Jensen, J.S.; Unemo, M. In vitro activity of the new fluoroketolide solithromycin (CEM-101) against a large collection of clinical Neisseria gonorrhoeae isolates and international reference strains, including those with high-level antimicrobial resistance: Potential treatment option for gonorrhea? Antimicrob. Agents Chemother. 2012, 56, 2739-2742. [PubMed]

27. Hook, E.W., 3rd; Golden, M.; Jamieson, B.D.; Dixon, P.B.; Harbison, H.S.; Lowens, S.; Fernandes, P. A Phase 2 Trial of Oral Solithromycin $1200 \mathrm{mg}$ or $1000 \mathrm{mg}$ as Single-Dose Oral Therapy for Uncomplicated Gonorrhea. Clin. Infect. Dis. 2015, 61, 1043-1048. [CrossRef] [PubMed]

28. Huband, M.D.; Bradford, P.A.; Otterson, L.G.; Basarab, G.S.; Kutschke, A.C.; Giacobbe, R.A.; Patey, S.A.; Alm, R.A.; Johnstone, M.R.; Potter, M.E.; et al. In vitro antibacterial activity of AZD0914, a new spiropyrimidinetrione DNA gyrase/topoisomerase inhibitor with potent activity against Gram-positive, fastidious Gram-Negative, and atypical bacteria. Antimicrob. Agents Chemother. 2015, 59, 467-474. [CrossRef] [PubMed]

29. Unemo, M.; Ringlander, J.; Wiggins, C.; Fredlund, H.; Jacobsson, S.; Cole, M. High in vitro susceptibility to the novel spiropyrimidinetrione ETX0914 (AZD0914) among 873 contemporary clinical Neisseria gonorrhoeae isolates from 21 European countries from 2012 to 2014. Antimicrob. Agents Chemother. 2015, 59, 5220-5225. [CrossRef] [PubMed]

30. Farrell, D.J.; Sader, H.S.; Rhomberg, P.R.; Scangarella-Oman, N.E.; Flamm, R.K. In vitro Activity of Gepotidacin (GSK2140944) against Neisseria gonorrhoeae. Antimicrob. Agents Chemother. 2017, 61, e02047-16. [CrossRef] [PubMed] 
31. Taylor, S.N.; Morris, D.H.; Avery, A.K.; Workowski, K.A.; Batteiger, B.E.; Tiffany, C.A.; Perry, C.R.; Raychaudhuri, A.; Scangarella-Oman, N.E.; Hossain, M.; et al. Gepotidacin for the Treatment of Uncomplicated Urogenital Gonorrhea: A Phase 2, Randomized, Dose-Ranging, Single-Oral Dose Evaluation. Clin. Infect. Dis. 2018. [CrossRef] [PubMed]

32. Jacobsson, S.; Paukner, S.; Golparian, D.; Jensen, J.S.; Unemo, M. In vitro activity of the novel pleuromutilin lefamulin (BC-3781) and effect of efflux pump inactivation on multidrug-resistant and extensively-drug resistant Neisseria gonorrhoeae. Antimicrob. Agents Chemother. 2017, 61, e01497. [CrossRef] [PubMed]

33. Paukner, S.; Gruss, A.; Jensen, J.S. In Vitro Activity of Lefamulin against Sexually Transmitted Bacterial Pathogens. Antimicrob. Agents Chemother. 2018, 62, e02380-17. [CrossRef] [PubMed]

34. Butler, M.M.; Waidyarachchi, S.L.; Connolly, K.L.; Jerse, A.E.; Chai, W.; Lee, R.E.; Kohlhoff, S.A.; Shinabarger, D.L.; Bowlin, T.L. Aminoethyl spectinomycins as therapeutics for drug-resistant gonorrhea and chlamydial co-infections. Antimicrob. Agents Chemother. 2018, 65. [CrossRef]

35. Fedarovich, A.; Djordjevic, K.A.; Swanson, S.M.; Peterson, Y.K.; Nicholas, R.A.; Davies, C. High-Throughput Screening for Novel Inhibitors of Neisseria gonorrhoeae Penicillin-Binding Protein 2. PLoS ONE 2012, 7, e44918. [CrossRef] [PubMed]

36. Liu, Y.; Perez, J.; Hammer, L.A.; Gallagher, H.C.; de Jesus, M.; Egilmez, N.K.; Russell, M.W. Intravaginal Administration of Interleukin 12 during Genital Gonococcal Infection in Mice Induces Immunity to Heterologous Strains of Neisseria gonorrhoeae. mSphere 2018, 3, e00421. [CrossRef] [PubMed]

37. Foschi, C.; Salvo, M.; Cevenini, R.; Parolin, C.; Vitali, B.; Marangoni, A. Vaginal Lactobacilli Reduce Neisseria gonorrhoeae Viability through Multiple Strategies: An in vitro Study. Front. Cell Infect. Microbiol. 2017, 7, 502. [CrossRef] [PubMed]

38. Darling, E.K.; McDonald, H. A meta-analysis of the efficacy of ocular prophylactic agents used for the prevention of gonococcal and chlamydial ophtalmia neonatorum. J. Midwif. Womens Health 2010, 55, 319-327. [CrossRef] [PubMed]

39. Churchward, C.P.; Alany, R.G.; Kirk, R.S.; Walker, A.J.; Snyder, L.A.S. Prevention of Ophthalmia Neonatorum Caused by Neisseria gonorrhoeae Using a Fatty Acid-Based Formulation. MBio 2017, 8, e00534-17. [CrossRef] [PubMed]

40. Connor, D.O.; Zantow, J.; Hust, M.; Bier, F.F.; von Nickisch-Rosenegk, M. Identification of Novel Immunogenic Proteins of Neisseria gonorrhoeae by Phage Display. PLoS ONE 2016, 11, e0148986. [CrossRef] [PubMed]

41. Sikora, A.E.; Mills, R.H.; Weber, J.V.; Hamza, A.; Passow, B.W.; Romaine, A.; Williamson, Z.A.; Reed, R.W.; Zielke, R.A.; Korotkov, K.V. Peptide Inhibitors Targeting the Neisseria gonorrhoeae Pivotal Anaerobic Respiration Factor AniA. Antimicrob. Agents Chemother. 2017, 61, e00186-17. [CrossRef] [PubMed]

42. Biedenbach, D.J.; Bouchillon, S.K.; Hackel, M.; Miller, L.A.; Scangarella-Oman, N.E.; Jakielaszek, C.; Sahm, D.F. In Vitro Activity of Gepotidacin, a Novel Triazaacenaphthylene Bacterial Topoisomerase Inhibitor, against a Broad Spectrum of Bacterial Pathogens. Antimicrob. Agents Chemother. 2016, 60, 1918-1923. [CrossRef] [PubMed]

43. Churchward, C.P.; Calder, A.; Snyder, L.A.S. Mutations in Neisseria gonorrhoeae grown in sub-lethal concentrations of monocaprin do not confer resistance. PLoS ONE 2018, 13, e0195453. [CrossRef] [PubMed]

44. Golkar, K.; Bagasra, O.; Pace, D.G. Bacteriophage therapy: A potential solution for the antibiotic resistance crisis. J. Infect. Dev. Ctries. 2014, 8, 129-136. [CrossRef] [PubMed]

45. Lin, D.M.; Koskella, B.; Lin, H.C. Phage therapy: An alternative to antibiotics in the age of multi-drug resistance. World J. Gastrointest. Pharmacol. Ther. 2017, 8, 162-173. [CrossRef] [PubMed]

(C) 2018 by the authors. Licensee MDPI, Basel, Switzerland. This article is an open access article distributed under the terms and conditions of the Creative Commons Attribution (CC BY) license (http:/ / creativecommons.org/licenses/by/4.0/). 